Fernando Mussa Abujamra Aith ${ }^{1}$ Ana Claudia Camargo Germani ${ }^{1}$ Rachelle Balbinot ${ }^{1}$ Sueli Gandolfi Dallari ${ }^{1}$

\title{
REGULAÇÃO DO EXERCÍCIO DE PROFISSÕES DE SAÚDE: FRAGMENTAÇÃO E COMPLEXIDADE DO MODELO REGULATÓRIO BRASILEIRO E DESAFIOS PARA SEU APERFEIÇOAMENTO*
}

Health professions regulation: Fragmentation and complexity of the Brazilian model and challenges for its improvement

${ }^{1}$ Universidade de São Paulo. São Paulo/SP, Brasil.

Correspondência: Fernando Aith. E-mail: fernando.aith@usp.br

Recebido: 02/07/2018. Revisado: 20/08/2018. Aprovado: 28/08/2018.

*Artigo original desenvolvido no âmbito da pesquisa “Regulação das profissões de saúde no Brasil: mapeamento jurídico e institucional, identificação dos pontos de articulação e desarticulação e formulação de propostas para a harmonização regulatória", realizada pelo Centro de Estudos e Pesquisas de Direito Sanitário (Cepedisa) em 2016 / 2018. 


\section{RESUMO}

A regulação jurídica das profissões de saúde no Brasil é composta por um conjunto normativo amplo, complexo e fragmentado, que encontra sua base na Constituição Federal de 1988 e se complementa por uma extensa quantidade de leis, decretos, portarias e, principalmente, resoluções editadas pelos conselhos profissionais. O presente artigo tem como objetivo identificar os principais marcos legais que estruturam a regulação do exercício profissional no setor da saúde brasileiro, delineando, a partir dos resultados obtidos, o modelo de regulação do exercício de profissões de saúde no brasil. o método utilizado foi de pesquisa normativa e jurisprudencial, com análise qualitativa dos dados selecionados. A partir das leis atualmente vigentes, foram identificadas as diferentes instituições estatais com competência legal para regular as profissões de saúde no Brasil e as principais normas editadas para a regulação das profissões de saúde. Em seguida, buscaram-se conflitos regulatórios judicializados por essas instituições e levados até os tribunais superiores. A análise das leis e decisões selecionadas permitiu a caracterização do que denominamos Modelo de Regulação de Profissões de Saúde Brasileiro, com a identificação e análise das diferentes instituições estatais reguladoras e das principais normas vigentes que regulam as 14 profissões de saúde reconhecidas pelo Conselho Nacional de Saúde. Os resultados apresentados neste artigo delineiam o atual modelo de regulação de profissões de saúde vigente no brasil e contribuem para o aprofundamento dos conhecimentos sobre o tema, possibilitando reflexões para o aperfeiçoamento do atual modelo jurídico-institucional brasileiro.

\section{Palavras-Chave}

Direito Sanitário; Modelo Regulatório; Profissões de Saúde; Regulação da Saúde; Regulação de Profissões de Saúde.

\section{ABSTRACT}

The legal regulation of health professions in Brazil is composed by a set of broad, complex and fragmented norms, based on the Federal Constitution of 1988 (CF 88) and complemented by an extensive amount of laws, decrees, ordinances, and mainly resolutions issued by the professional councils. This article aims to identify the main legal frameworks that structure the regulation of professional practice in the Brazilian health sector, using the results to outline a model of regulation of the Health Professions in Brazil. The method used was normative and jurisprudential research followed by a qualitative analysis of the selected data. Based on the current laws, we first identified the different state institutions with legal competence to regulate the health professions in Brazil and the main edited norms for that purpose. Next, we searched for the regulatory conflicts brought by these institutions before the higher courts. The analysis of the selected laws and decisions allowed the characterization of what we call the Brazilian Health Professions Regulation Model, with the identification and analysis of the different state regulatory institutions and the main current norms that regulate the 14 health professions recognized by the National Health Council. The results presented in this article outline the current Model of Regulation of Health Professions in force in Brazil and contribute to the deepening of knowledge on the subject, allowing reflections for the improvement of the current Brazilian legal-institutional model.

\section{Keywords}

Health Law; Health Professions; Health Professions Regulation; Health Regulation; Regulatory Model. 


\section{Introdução}

Reconhecido como direito humano fundamental e dever do Estado brasileiro, o direito à saúde exige, para sua efetivação, políticas públicas econômicas e sociais voltadas à promoção, prevenção e recuperação da saúde individual e coletiva. Para que o Estado seja capaz de implementar políticas públicas voltadas à plena realização do direito à saúde, a regulação estatal sobre a formação e o exercício profissional no campo da saúde consolida-se como um tema estratégico e estruturante do sistema de saúde nacional, com efeitos tanto no sistema público quanto no sistema privado.

A regulação jurídica das profissões de saúde no Brasil é composta por um conjunto normativo amplo, complexo e fragmentado, que encontra sua base na Constituição Federal de 1988 (CF/1988) e se complementa por uma extensa e variada quantidade de leis, decretos, portarias e, principalmente, resoluções editadas pelos conselhos profissionais. Ao longo do século XX, especialmente a partir da década de 1950, foram sendo aprovadas diversas leis federais que deram origem ao atual modelo de regulação de profissões de saúde no Brasil.

Além da fragmentação e da complexidade, a regulação das profissões de saúde vigente hoje também padece de desatualização. Grande parte das leis que orientam o exercício das profissões de saúde e organizam os respectivos conselhos profissionais foi criada antes mesmo da promulgação da CF/1988 e da criação do Sistema Único de Saúde (SUS). Essa complexa realidade regulatória representa um obstáculo à implantação do SUS como política de Estado, comprometendo assim o cumprimento, pelo próprio Estado, de seu dever de garantir o direito à saúde (CF/1988, arts. $6^{\circ}$ e de 196 a 200$)^{1}$.

O Conselho Nacional de Saúde (CNS), por meio da Resolução n. 287/1998, definiu que as seguintes categorias profissionais de nível superior possuem área de atuação diretamente relacionada com o sistema de saúde e com a efetivação do direito à saúde pelo Estado brasileiro: assistentes sociais, biólogos, biomédicos, profissionais de educação física, enfermeiros, farmacêuticos, fisioterapeutas, fonoaudiólogos, médicos, médicos veterinários, nutricionistas, odontólogos, psicólogos e terapeutas ocupacionais ${ }^{2}$.

Para se ter uma ideia da dimensão do modelo de regulação de profissões de saúde no Brasil, apenas no que se refere às 14 profissões de ensino superior mencionadas pelo CNS a legislação correspondente à regulação do exercício profissional é

\footnotetext{
${ }^{1}$ BRASIL. Constituição da República Federativa do Brasil de 1988. Disponível em: <http://www.planalto.gov. br/ccivil_03/constituicao/constituicaocompilado.htm>. Acesso em: 22 mar. 2017.

${ }^{2}$ BRASIL. Ministério da Saúde. Conselho Nacional de Saúde. Resolução CNS n. 287 de 08 de outubro de 1998. Disponível em: <http://bvsms.saude.gov.br/bvs/saudelegis/cns/1998/res0287_08_10_1998. html>. Acesso em: 22 mar. 2017.
} 
orientada por centenas de normas jurídicas constitucionais, legais e, sobretudo, infralegais, tais como decretos, portarias e resoluções. Essas normas jurídicas são publicadas por distintas instituições estatais regulatórias dos poderes Executivo e Legislativo.

A miríade legislativa do modelo de regulação nacional fragmenta a regulação sobre as profissões de saúde no país e gera um cenário jurídico bastante complexo, propenso a gerar insegurança jurídica para os cidadãos, para os profissionais e, inclusive, para o próprio Estado regulador devido a contradições, paradoxos, conflitos de competências etc.

O presente artigo tem como objetivo identificar os principais marcos legais que estruturam a regulação do exercício profissional no setor da saúde brasileiro, elaborando, a partir dos resultados obtidos, um desenho preciso e compreensível do atual modelo de regulação do exercício de profissões de saúde no Brasil.

\section{A regulação de profissões de saúde como função estatal: delimitando o conceito}

Em sentido amplo, o termo "regulação" diz respeito às regras, às leis, à moral, enfim, a qualquer instrumento formal ou informal que imponha limites e determine deveres. Dada a amplitude de seu alcance, o conceito de regulação é polissêmico e pode se referir a diferentes significados, o que é especialmente verificado no campo da saúde pública ${ }^{3}$. O presente artigo busca compreender a regulação das profissões de saúde no Brasil a partir do enfoque jurídico do termo "regulação", ou seja, a partir do reconhecimento da regulação como uma função estatal necessária para o cumprimento dos diversos deveres atribuídos constitucionalmente ao Estado Democrático de Direito brasileiro.

O fenômeno da regulação estatal deve ser entendido, no Direito moderno, como uma consequência da evolução do Estado de Direito. Em sentido amplo, a regulação de profissões de saúde mostra-se como uma função do Estado, necessária para o cumprimento dos diversos deveres a ele atribuídos, para a proteção dos direitos humanos e para uma boa organização da sociedade.

A função estatal de regular está associada ao dever fundamental do Estado de ordenar o corpo social para que este se organize harmonicamente. A regulação existe para possibilitar a consecução dos objetivos coletivos pactuados pelo corpo social, no Brasil expressamente previstos pelo artigo $3^{\circ}$ da CF/1988, a saber:

i) construir uma sociedade livre, justa e solidária; ii) garantir o desenvolvimento nacional; iii) erradicar a pobreza e a

\footnotetext{
${ }^{3}$ SANTOS, Fausto Pereira dos; MERHY, Emerson Elias. A regulação pública da saúde no Estado brasileiro: uma revisão. Interface, Botucatu [online], v. 10, n. 9, p. 25-41, 2006. ISSN 1414-3283. Disponível em: <http://www.scielo.br/pdf/icse/v10n19/a03v1019.pdf>. $\quad$ http://dx.doi.org/10.1590/S141432832006000100003.
} 
marginalização e reduzir as desigualdades sociais e regionais; iv) promover o bem de todos, sem preconceitos de origem, raça, sexo, cor, idade e quaisquer outras formas de discriminação.

No campo da saúde pública, a regulação estatal deve garantir a saúde como direito de todos e dever do Estado (CF/1988, art. 196). Em síntese, a regulação do exercício profissional no campo da saúde deve ser realizada para que os profissionais de saúde, em sua atuação, sejam vetores do desenvolvimento social rumo aos objetivos nacionais listados pela Constituição.

A função estatal de regulação engloba pelo menos seis diferentes tipos de competências jurídicas: (i) competência normativa: abrange toda a atividade estatal voltada à produção de normas jurídicas que determinem direitos, imponham deveres e definam obrigações, inclusive prevendo, quando necessário, mecanismos de sanção aos que não observarem seus ditames; (ii) competência adjudicatória: competência para autorizar e permitir previamente o exercício de uma determinada função ou profissão, por meio da exigência e do fornecimento de registros, autorizações ou certificados de habilitação, por exemplo; (iii) competência de fiscalização: entendida, de maneira geral, como a atividade de fiscalizar, acompanhar, verificar, censurar e sindicar as ações e as omissões desenvolvidas dentro da sociedade, abrangendo as ações e omissões tanto estatais como particulares; (iv) competência de sanção ou aplicação de penalidades: atribuição estatal voltada à aplicação de penalidades a quem porventura não cumprir uma determinada obrigação social imposta; (v) competência arbitral: envolve as mediações e arbitragens de eventuais conflitos sociais existentes, podendo ocorrer nas esferas administrativa e/ou judicial e; (vi) competência de indução: competência pela qual o Estado, através de recomendações pautadas pelo planejamento político e administrativo, orienta as ações dos atores sociais que detêm a competência técnica para que atendam ao interesse de desenvolvimento do Estado.

A função de regulação do Estado aumenta à medida que este fica cada vez mais complexo, no que se refere tanto às diversidades sociais existentes como, principalmente, a uma necessidade de dinamização do direito como instrumento estatal de controle e organização social. Especificamente no que diz respeito à regulação de profissões de saúde, a atividade regulatória estatal está voltada a garantir que as atividades de interesse para a saúde sejam exercidas por profissionais com formação adequada, habilitação técnica apropriada e conduta ética de acordo com os parâmetros sociais estabelecidos normativamente.

Como atividade estatal, a regulação das profissões de saúde é realizada pelos três poderes: o Poder Legislativo regula por meio da aprovação de leis e com a fiscalização do Poder Executivo; o Poder Executivo regula por meio da produção de normas jurídicas infralegais e da implementação de políticas públicas; e o Poder Judiciário regula por meio de decisões tomadas no âmbito 
de processos judiciais, arbitrando conflitos instalados na sociedade e regulando os casos concretos. Sundfeld, ao comentar a questão da regulação em relação ao princípio da separação dos poderes, lembra que atualmente "é preciso que o Estado vá trabalhando com a realidade todo o tempo, para definir situações que se põem"4. Exemplifica com a necessidade de o Estado estar, constantemente, definindo situações que se alteram de forma extremamente dinâmica e que se mostram desprovidas de conhecimentos técnicos aprofundados (como definir o nível de poluentes aceitável numa determinada época do ano, ou situação de fato). A indagação feita por Sundfeld sobre a nova realidade histórica da regulação é instigante: seria viável, dentro das demandas normativas atuais, supor que o legislador possa dedicar-se a um verdadeiro gerenciamento normativo da realidade? Responde o autor informando que, a seu ver, "nem o modo de produção de normas que conhecemos - que fez nascer o Código Civil - nem o modelo tradicional de solução de conflitos - o do julgamento de ações pelo Poder Judiciário - bastam nos novos tempos".

A função regulatória do Estado, em especial em suas competências normativa, de fiscalização e adjudicatória, aumentou muito a partir da privatização e da reestruturação dos serviços de titularidade estatal, inclusive aqueles que eram executados por monopólio. Aumentou, ainda, com a criação de agências reguladoras responsáveis por determinados setores da sociedade. No campo da regulação de profissões de saúde, tal realidade é ainda mais evidente pela diversidade de instituições aptas a regular normativamente neste campo: cada conselho profissional possui competências normativas específicas para regular o exercício profissional em sua esfera de competência.

O presente artigo adota, assim, o conceito de regulação como função estatal de titularidade comum aos três poderes do Estado - Legislativo, Executivo e Judiciário - em cujo conteúdo reúne uma gama diversificada de atividades voltadas a intervir na sociedade, seja emitindo normas jurídicas legais e infralegais, seja assumindo integralmente determinadas responsabilidades sociais para seu exercício de forma direta, seja induzindo a sociedade para que desenvolva ações em busca dos objetivos do Estado, seja impondo aos particulares sanções voltadas à preservação do interesse público.

Dentro de suas diversas competências, acima delineadas, a função estatal de regular tem na competência normativa seu eixo estruturante. A regulação normativa, considerada em sentido amplo, reúne tanto a atividade legislativa de produção das leis quanto a atividade normativa de produção de atos normativos infralegais pelo Poder Executivo. Dentre esses atos infralegais regulatórios, situam-se as normas exaradas pelos ministérios e pelos conselhos profissionais, por exemplo.

${ }^{4}$ SUNDFELD, Carlos Ari. Direito administrativo econômico. 1. ed. São Paulo: Malheiros Ed., 2002. p. 28-29. 


\section{Limites e condicionantes da regulação normativa estatal}

Conforme visto acima, o direito necessita atualizar-se para ser instrumento útil e eficaz para a sociedade. Chevalier mostrou que o Direito moderno funda-se sob o signo da razão, com as características da generalidade, da sistematização e da estabilidade 5 . O Direito moderno também estaria embasado na noção de que todos os seres humanos nascem iguais e dotados de direitos, e de que o Estado deve preservar as liberdades individuais. A partir do desenvolvimento do Estado social, o direito foi perdendo suas características de generalidade e estabilidade; a lei também seguiu esse caminho, tornando-se mais abrangente e multiforme. O princípio da generalidade foi sendo deixado de lado à medida que a lei passava a ser instrumento de governo para ações sociais. Nesse movimento, foi-se também a estabilidade da lei, que passou a ser sujeitada a pressões políticas. Até a noção do individualismo sofreu temperanças, quando o Estado social passou a impor uma lógica na qual o indivíduo deve submeter-se à lei e ao bem comum.

Chevalier sustenta, assim, que o Estado-Providência acarretou uma crise do Direito ao minar suas características gerais iniciais, obrigando a sociedade a repensá-lo à luz da nova realidade, na qual o direito possui ingredientes de antimodernidade e de pós-modernidade.

Os aspectos de antimodernidade apontados são a complexidade e a flexibilidade. O Direito moderno, baseado na razão, tinha no Estado seu produtor. Na nova fase, ocorre o pluralismo das fontes de produção (Direito Internacional e Comunitário, autorregulação, poder de codeterminação do Poder Judiciário), dando uma complexidade maior ao direito. Nesse sentido, Chevalier também ressalta o papel do contrato e a ideia de participação do cidadão na elaboração do direito. Daí o surgimento das consultas públicas, das audiências públicas, dos referendos. A flexibilidade também é uma tendência que aponta para aspectos negativos, na medida em que o direito é formado cada vez mais por "leis-quadro" - leis estas que deixam espaços abertos para que o Poder Executivo possa completar (regulamentar) seu conteúdo com larga margem discricionária, já que tais leis possuem abundância em conceitos jurídicos indeterminados (droit mou). A norma jurídica tende, então, a ser englobada no tema mais largo da regulação, em que são adotados diversos instrumentos normativos que vão além da lei e que, embora não possuam a força da lei, apresentam força jurídica semelhante.

No campo da regulação de profissões de saúde no Brasil, tal realidade é bastante visível, na ampla gama seja de resoluções normativas exaradas pelos conselhos profissionais, seja de portarias e resoluções exaradas pelos ministérios e conselhos competentes. Estas normas, embora exaradas pelo Poder Executivo, impõem aos

\footnotetext{
${ }^{5}$ CHEVALIER, Jacques. Vers un droit posmoderne. In: CLAM, Jean; MARTIN, Gille (Dirs.). Transformations de la regulation juridique. Paris: LGDJ, 1998.
} 
administrados diversas obrigações primárias, representando uma nova realidade jurídica, ao mesmo tempo complexa e flexível.

O direito pós-moderno apresentado por Chevalier também tem características de hipermodernidade, pois aponta para o reforço do individualismo e do racionalismo. A razão será mais prática e estará presente no conteúdo e na forma de elaboração do direito. A hierarquia normativa tende a ser preservada, para manter a coerência sistêmica, com a constitucionalização dos direitos fundamentais e a paulatina harmonização dos novos elementos do direito, através de inovações normativas ou da própria jurisprudência. As normas baixadas pelos agentes reguladores, que não o Poder Legislativo, são harmonizadas pelo Poder Judiciário, que as incorpora ao sistema. A racionalização do processo de elaboração das leis e normas em geral caminha para o devido processo legal substantivo, que será objeto de um controle mais rígido por parte da sociedade, que por sua vez verificará não só os aspectos formais, mas principalmente o conteúdo material da norma produzida e sua adequação aos ditames da Lei Maior (Constituição) e dos demais princípios e valores que regem a sociedade.

Chevalier destaca, assim, quatro aspectos fundamentais de hipermodernidade identificados no Direito pós-moderno: (i) a racionalização aparece como exacerbação do direito racional de outrora, colocando a ciência como um instrumento auxiliar do direito e desenvolvendo mecanismos cada vez mais dinâmicos e "científicos" de interação entre o direito e a sociedade; (ii) pan-jurisdicionalização do direito, que passa a atingir todas as relações sociais; (iii) necessidade crescente de segurança; e (iv) preocupação cada vez maior com a proteção dos direitos humanos.

Essas lições de Chevalier são relevantes porque, no modelo de regulação de profissões de saúde brasileiro, pode-se perceber que o Poder Legislativo ainda tem a faculdade de vincular a administração, valendo-se do princípio da legalidade e da manutenção da hierarquia normativa como paradigma vigente do direito. Mas há que se compreender que, nas sociedades complexas do mundo contemporâneo, existe a possibilidade e, mais ainda, a necessidade de o Poder Legislativo, em diversos assuntos, delegar a tarefa normativa para órgãos reguladores ou para o poder regulamentar. A zona de discricionariedade da regulação e da regulamentação a serem exercidas pelo Poder Executivo continua limitada pela lei, mas esta tem a possibilidade de expressamente tornar essa zona de discricionariedade bastante ampla. $\mathrm{E}$ é justamente este o cenário do modelo brasileiro: leis-quadro que criam profissões e conselhos profissionais com vasto poder regulador autônomo, concedendo a tais conselhos e seus integrantes um alto grau de discricionariedade normativa.

\section{Regulação do exercício de profissões de saúde no Brasil: contexto normativo e institucional introdutório}

De acordo com o artigo 5, inciso XIII, da CF/1988, "é livre o exercício de qualquer trabalho, ofício ou profissão, atendidas as qualificações profissionais que 
a lei estabelecer". A competência legislativa para regulação de profissões no Brasil é privativa da União, de acordo com o inciso XVI do artigo 22 da CF/1988.

Sendo assim, o direito à saúde, reconhecido como um direito humano fundamental pelo artigo $6^{\circ} \mathrm{da} \mathrm{CF} / 1988$, depende, para ser efetivado, do exercício de um conjunto de ações e serviços a serem prestados por essas 14 profissões, juntamente com um expressivo conjunto de profissionais técnicos que atuam no sistema de saúde brasileiro, tanto no sistema público quanto no privado.

Os serviços de saúde no Brasil foram reconhecidos como de relevância pública pelo artigo 197 da CF/1988. Tais serviços são viabilizados por profissionais que atuam após receberem formação específica, sob princípios científicos afins e emanados para um interesse social comum - a saúde, direito de todos e dever do Estado. Sob o princípio da integralidade, exigem-se do Estado ações e serviços integrais que deem conta da promoção, prevenção e recuperação da saúde individual e coletiva.

Ao especificar o sistema de saúde brasileiro em seus artigos 6º de 196 a 200, a CF/1988 definiu a saúde como um direito fundamental a ser garantido pelo Estado, englobando, assim, uma atividade regulatória intensa do Estado para fins de proteção da saúde dos brasileiros. Dentre as atividades regulatórias inseridas no campo do sistema de saúde brasileiro, estão as inerentes à regulação do exercício profissional das profissões de saúde no país.

A regulação das profissões de saúde é determinada, preliminarmente, pelas leis que regulamentam essas profissões e criam os correspondentes conselhos profissionais. Em linhas gerais, pode-se dizer que a natureza jurídica dos conselhos é autárquica, com fundamento no artigo $5^{\circ}$, inciso XIII, no artigo 21 , inciso XXIV, e no artigo 22, inciso XVI da CF/1988, combinados com o disposto nas leis de criação dos conselhos profissionais e no Decreto-Lei n. $200 / 1967^{6}$. No entanto, a pesquisa realizada mostrou que ainda há grande discussão teórica sobre a real natureza jurídica dos conselhos profissionais, conforme aprofundado mais adiante.

Em sede introdutória, vale destacar que cada um dos conselhos profissionais possui competências normativo-regulatórias sobre suas respectivas profissões. Assim, são os conselhos profissionais que definem as competências e atividades que podem ser exercidas por seus profissionais registrados. Cada conselho possui autonomia regulatória, editando um conjunto expressivo de normas jurídicas (normalmente resoluções), que definem na prática o que pode e o que não pode fazer um profissional de saúde no Brasil. Esse quadro se reflete em conflitos entre os conselhos e a sociedade ou entre os próprios conselhos, conflitos estes que via de regra são judicializados e dizem respeito especificamente ao círculo de competências legais dos profissionais

\footnotetext{
${ }^{6}$ BRASIL. Decreto-Lei n. 200, de 25 de fevereiro de 1967. Dispõe sôbre a organização da Administração Federal, estabelece diretrizes para a Reforma Administrativa e dá outras providências. Disponível em: <http://www.planalto.gov.br/ccivil_03/decreto-Lei/Del0200compilado.htm>. Acesso em: 03 set. 2018.
} 
de saúde. Além disso, também possuem influência sobre a regulação do exercício profissional das profissões de saúde no Brasil algumas normas jurídicas infralegais emanadas por órgãos da Administração Direta da União, tais como o Ministério da Saúde, o Ministério do Trabalho e Emprego e o Ministério da Educação.

Mapear essas normas e verificar sua harmonização com as normas editadas pelos conselhos profissionais é uma tarefa fundamental atualmente para evitar uma dissociação entre o interesse público de garantir o direito à saúde e os interesses específicos e corporativos das diferentes profissões de saúde. O mapeamento normativo e institucional permitirá uma melhor compreensão de quais são as instituições responsáveis pela regulação das profissões de saúde e de quais são as normas jurídicas constitucionais, legais e infralegais que, empiricamente, orientam as atividades dos profissionais de saúde hoje no país.

Trata-se de um esforço de revisão sobre a atual regulação incidente sobre as profissões de saúde para que se possa: compreender o modelo nacional a partir da identificação de sua atual configuração; identificar os obstáculos que essa regulação impõe para o desenvolvimento do SUS; e formular propostas de adequação, atualização e harmonização regulatória visando à plena efetivação do direito à saúde. A revisão a ser realizada também visa a identificar os mecanismos jurídico-administrativos existentes para a articulação e harmonização da regulação das profissões de saúde atualmente existentes no país.

\section{Métodos}

Para uma compreensão adequada da atual regulação jurídico-normativa das profissões de saúde no Brasil, foi desenvolvido o projeto denominado "Regulação das profissões de saúde no Brasil: mapeamento jurídico e institucional, identificação de pontos de articulação e desarticulação e formulação de propostas para a harmonização regulatória", que contou com o financiamento da Organização Pan-Americana de Saúde (OPAS).

O método utilizado foi de pesquisa normativa, documental e jurisprudencial, com análise qualitativa dos dados. A análise qualitativa foi realizada sobre os documentos normativos oficiais publicados pelas instituições e autoridades competentes para regular a formação e o exercício profissional na área da saúde no país, bem como sobre os processos judiciais cujos autores ou réus são as instituições reguladoras e cujo objeto é o escopo de competência das profissões ou das instituições reguladoras.

Por documentos normativos entendem-se todos os tipos de normas jurídicas oficiais, publicadas no Diário Oficial da União e aplicáveis ao tema, notadamente leis federais, decretos federais, resoluções de instituições e órgãos federais competentes e outros documentos com poder normativo, ainda que de baixa densidade, como os pareceres normativos. A seleção de normas e documentos jurídicos analisados foi feita 
por meio de buscas nas bases de dados do Palácio do Planalto, do Congresso Nacional e dos ministérios da Saúde, do Trabalho, do Planejamento, da Educação e da Justiça. Nessas bases de dados, foram buscadas as normas que regulam as 14 profissões de saúde listadas pela Resolução CNS n. 287/1998, a partir dos seguintes termos: Conselhos Profissionais, Conselho Federal de (profissão), profissões de saúde, regulação de profissões de saúde. As normas obtidas com a busca inicial foram selecionadas a partir de seu conteúdo, quando representavam normas de configuração do modelo nacional (criação de órgãos e instituições e definição de competências institucionais).

A pesquisa jurisprudencial consistiu na busca de decisões judiciais dos tribunais superiores sobre a natureza jurídica dos conselhos profissionais no Brasil, bem como de decisões tomadas em processos em que os conselhos figuravam no polo passivo ou ativo e o objeto da ação continha conflito de competências regulatórias. A pesquisa processual foi realizada por meio da página virtual oficial do Superior Tribunal de Justiça (STJ), e os termos buscados foram os nomes dos conselhos marcados nas posições de "autor", "réu" e "outros". Usando a ferramenta de busca desses dois sites, foram identificadas todas as ações que continham algum dos conselhos profissionais de saúde objetos da pesquisa, tanto no polo ativo quanto no passivo das demandas. No primeiro resultado, foram identificadas 52 ações referindo os conselhos; após uma análise preliminar dos elementos da ação, deste universo foram selecionadas 23 ações que versavam a respeito de competência profissional para uma análise mais aprofundada do objeto da ação, bem como dos argumentos e competências em conflito.

O estudo foi submetido ao Comitê de Ética em Pesquisa da Faculdade de Medicina da Universidade de São Paulo e aprovado em 6 de maio de 2015 (Protocolo de Pesquisa n. 060/15).

\section{Modelo regulatório do exercício profissional no setor da saúde no Brasil}

A pesquisa realizada permitiu sintetizar o que denominamos aqui como o modelo de regulação de profissões de saúde no Brasil. Os resultados obtidos foram organizados de forma a apresentar de maneira clara e objetiva de que forma o Estado brasileiro se organiza para executar sua função de regular o exercício profissional no setor da saúde do país.

Considerando que a regulação de profissões de nível superior no país é competência privativa da União, nos termos do artigo 22, inciso XVI, da CF/1988, o presente artigo concentra-se em apresentar os marcos legais que configuram o que podemos denominar de leis-quadro federais da regulação de profissões de saúde no país, bem como as principais instituições das administrações Direta e Indireta da União atualmente responsáveis por tal regulação - no que se refere tanto às competências regulatórias normativas quanto às competências regulatórias de fiscalização, adjudicação, aplicação de penalidades, arbitragem e indução. 
Em seguida, o presente texto irá discutir alguns efeitos que a fragmentação normativa e institucional do atual modelo regulatório brasileiro tem sobre a regulação do exercício profissional de saúde no país. Dentre os efeitos a serem destacados, estão o surgimento e a judicialização de conflitos regulatórios entre diferentes instituições estatais, com reflexos diretos na organização da política e do sistema público de saúde no Brasil.

\section{Modelo de regulação do exercício de profissões de saúde no Brasil}

A regulação do exercício de profissões de saúde no Brasil é realizada, no âmbito da União, por um conjunto diversificado de órgãos da Administração Direta, tais como os ministérios, o Conselho Nacional de Saúde (CNS), a Câmara de Regulação do Trabalho em Saúde (CRTS) e a Mesa Nacional de Negociação Permanente do SUS (MNNP-SUS) e de instituições da Administração Indireta - conselhos profissionais das 14 diferentes categorias que compõem o leque de profissões de nível superior que atuam no setor da saúde.

Esse modelo regulatório, baseado em múltiplos órgãos da Administração Direta da União e em diversas instituições da Administração Indireta da União, todos com competências ao mesmo tempo específicas, complementares e, às vezes, superpostas e conflituosas, foi sendo construído por um conjunto amplo de leis aprovadas desde a década de 1950 até os dias atuais.

O Quadro 1 apresenta os principais órgãos da Administração Direta da União e suas respectivas competências legais relacionadas com a regulação de profissões de saúde no Brasil:

Além dos órgãos da Administração Direta acima listados, a regulação do exercício profissional no setor saúde é realizada de forma intensa pelos conselhos profissionais, instituições da Administração Indireta da União criadas ao longo da segunda metade do século XX por diversas leis que atualmente representam o marco normativo das 14 profissões da área da saúde reconhecidas como tal pelo CNS (Resolução n. 298/19987).

O Quadro 2 apresenta as principais leis que criam e oferecem as diretrizes regulatórias gerais (leis-quadro) das 14 profissões de ensino superior reconhecidas como categorias relacionadas com o sistema nacional de saúde pelo CNS, juntamente com a instituição estatal criada no âmbito da Administração Indireta para o exercício da função regulatória de cada profissão.

${ }^{7}$ BRASIL. Ministério da Saúde. Conselho Nacional de Saúde. Resolução n. 298, de 08 de outubro de 1998. Disponivel em: <http://bvsms.saude.gov.br/bvs/saudelegis/cns/1998/res0287_08_10_1998.html>. Acesso em: 03 set. 2018. 
Quadro 1. Órgãos da Administração Direta da União com competências para regulação de profissões de saúde no Brasil.

\begin{tabular}{|c|c|c|}
\hline Órgão & $\begin{array}{l}\text { Legislação definidora } \\
\text { de competências }\end{array}$ & $\begin{array}{l}\text { Principais competências de atuação no campo da regulação do } \\
\text { exercício profissional no setor da saúde }\end{array}$ \\
\hline $\begin{array}{l}\text { Presidência da } \\
\text { República }\end{array}$ & $\begin{array}{l}\text { CF/1988, arts. } 76 \\
\text { a } 84 \text {; } \\
\text { Lei n. } 13.502 / 2017 \\
\text { arts. } 2 \text { a } 20 \text {. }\end{array}$ & $\begin{array}{l}\text { Encaminhar projetos de lei sobre regulação de profissões ao } \\
\text { Congresso Nacional. } \\
\text { Sancionar ou vetar projetos de lei aprovados pelo Congresso Nacional. } \\
\text { Coordenar a Administração Pública da União, incluindo os ministros } \\
\text { das áreas específicas. }\end{array}$ \\
\hline Ministério da Justiça & $\begin{array}{l}\text { Lei n. } 13.502 / 2017 \\
\quad \text { art. } 47, \text { I e V. }\end{array}$ & $\begin{array}{l}\text { Defender a ordem jurídica, os direitos políticos e as garantias } \\
\text { constitucionais. } \\
\text { Defender a ordem econômica nacional e os direitos do consumidor }\end{array}$ \\
\hline $\begin{array}{l}\text { Ministério do } \\
\text { Planejamento, } \\
\text { Desenvolvimento } \\
\text { e Gestão }\end{array}$ & $\begin{array}{l}\text { Lei n. } 13.502 / 2017 \\
\text { arts. } 53, \text { IV e VII, } \\
\text { e } 54 .\end{array}$ & $\begin{array}{l}\text { Elaborar, acompanhar e avaliar o plano plurianual de investimentos } \\
\text { e dos orçamentos anuais. } \\
\text { Coordenar e administrar os sistemas de planejamento e orçamento } \\
\text { federal, de pessoal civil, de organização e modernização administrativa, de } \\
\text { administração de recursos da informação e informática e de serviços gerais. }\end{array}$ \\
\hline $\begin{array}{l}\text { Ministério da } \\
\text { Educação }\end{array}$ & $\begin{array}{l}\text { Lei } \mathrm{n} .13 .502 / 2017 \\
\quad \text { arts. } 37 \text { e } 38 .\end{array}$ & $\begin{array}{l}\text { Atuar na política nacional de educação. } \\
\text { Atuar na educação em geral, compreendendo ensino fundamental, } \\
\text { ensino médio, ensino superior, educação de jovens e adultos, } \\
\text { educação profissional, educação especial e educação a distância, } \\
\text { exceto ensino militar. } \\
\text { Cuidar da pesquisa e extensão universitária. }\end{array}$ \\
\hline $\begin{array}{l}\text { Ministério do } \\
\text { Trabalho }\end{array}$ & $\begin{array}{l}\text { Lei } \mathrm{n.} 13.502 / 2017 \\
\text { arts. } 55, \mathrm{III}, \mathrm{V} \text { e VI } \\
\text { e } 56 .\end{array}$ & $\begin{array}{l}\text { Atuar na formação e do desenvolvimento profissional. } \\
\text { Cuidar da segurança e saúde no trabalho. } \\
\text { Fiscalizar o trabalho, inclusive o trabalho portuário, e aplicar as } \\
\text { sanções previstas em normas legais ou coletivas. }\end{array}$ \\
\hline Ministério da Saúde & $\begin{array}{l}\text { Lei n. } 13.502 / 2017 \text {, } \\
\text { arts. } 64, \text { I, II, III e VIII, } \\
\text { e } 65 .\end{array}$ & $\begin{array}{l}\text { Cuidar da política nacional de saúde. } \\
\text { Coordenar e fiscalizar o SUS. } \\
\text { Atuar no campo da saúde ambiental e na promoção, proteção } \\
\text { e recuperação da saúde individual e coletiva, inclusive a dos } \\
\text { trabalhadores e dos índios. } \\
\text { Realizar pesquisas científica e tecnológicas na área de saúde. }\end{array}$ \\
\hline $\begin{array}{l}\text { Conselho Nacional } \\
\text { de Saúde }\end{array}$ & $\begin{array}{l}\text { Lei n. } 8.142 / 1990 \\
\text { art. } 1^{\circ} \text {, II, e } \S 2^{\circ} \text {. }\end{array}$ & $\begin{array}{l}\text { Formular estratégias e controlar a execução da política nacional } \\
\text { de saúde, inclusive nos aspectos econômicos e financeiros, } \\
\text { cujas decisões são homologadas pelo chefe do poder legalmente } \\
\text { constituído em cada esfera do governo. }\end{array}$ \\
\hline $\begin{array}{l}\text { Comissão Intersetorial } \\
\text { de Recursos } \\
\text { Humanos e Relação } \\
\text { de Trabalho - CIRHRT }\end{array}$ & $\begin{array}{l}\text { Resolução Conselho } \\
\text { Nacional de Saúde - } \\
\text { CNS n. } 287 / 1998\end{array}$ & $\begin{array}{l}\text { Definir as categorias profissionais do setor saúde e acompanhar a } \\
\text { política nacional de recursos humanos em saúde. }\end{array}$ \\
\hline $\begin{array}{l}\text { Mesa Nacional } \\
\text { de Negociação } \\
\text { Permanente do } \\
\text { SUS - MNNP/SUS }\end{array}$ & $\begin{array}{l}\text { Resolução Conselho } \\
\text { Nacional de Saúde } \\
\text {-CNS n. 331/2003 }\end{array}$ & $\begin{array}{l}\text { Acompanhar as condições do trabalho em saúde no Brasil e propor } \\
\text { medidas para sua melhoria. }\end{array}$ \\
\hline $\begin{array}{l}\text { Câmara de } \\
\text { Regulação do } \\
\text { Trabalho em Saúde }\end{array}$ & $\begin{array}{l}\text { Portaria GM/MS n. } \\
\text { 174/2006. }\end{array}$ & $\begin{array}{l}\text { Ligada ao Departamento de Gestão e da Regulação do Trabalho } \\
\text { na Saúde (DEGERTS), departamento da Secretaria de Gestão do } \\
\text { Trabalho e Educação na Saúde do Ministério da Saúde (SGTES-MS). } \\
\text { Debater as ações de regulação profissional para as profissões e } \\
\text { ocupações da área de saúde. } \\
\text { Sugerir mecanismos de regulação profissional da área de saúde. } \\
\text { Sugerir iniciativas legislativas visando a regular o exercício de novas } \\
\text { profissões e ocupações na área de saúde. }\end{array}$ \\
\hline
\end{tabular}

Elaboração própria. 
Quadro 2. Mapa normativo e institucional da Administração Indireta da União para a regulação do exercício de profissões de saúde no Brasil.

\begin{tabular}{|c|c|c|c|}
\hline Profissão & $\begin{array}{l}\text { Norma(s) } \\
\text { regulatória(s) }\end{array}$ & $\begin{array}{l}\text { Instituição da Administração } \\
\text { Indireta da União }\end{array}$ & $\begin{array}{l}\text { Natureza jurídica de } \\
\text { acordo com a lei de } \\
\text { criação do conselho }\end{array}$ \\
\hline $\begin{array}{l}\text { Assistente } \\
\text { Social }\end{array}$ & Lei n. 8.662/1993 & $\begin{array}{c}\text { Conselho Federal de Serviço } \\
\text { Social }\end{array}$ & $\begin{array}{l}\text { Norma não dispõe a } \\
\text { respeito }\end{array}$ \\
\hline Biólogo & Lei n. 6.684/1979 & Conselho Federal de Biologia & Autarquia federal \\
\hline Biomédico & Lei n. 6.684/1979 & $\begin{array}{l}\text { Conselho Federal } \\
\text { de Biomedicina }\end{array}$ & Autarquia federal \\
\hline $\begin{array}{l}\text { Profissional } \\
\text { de Educação } \\
\text { Física }\end{array}$ & Lei n. 9.696/1998 & $\begin{array}{l}\text { Conselho Federal } \\
\text { de Educação Física }\end{array}$ & $\begin{array}{l}\text { Norma não dispõe a } \\
\text { respeito }\end{array}$ \\
\hline Enfermeiro & $\begin{array}{l}\text { Lei n. 2.604/1955; } \\
\text { Lei n. 5905/1973; } \\
\text { Lei n. 7.498/1986 }\end{array}$ & $\begin{array}{l}\text { Conselho Federal de } \\
\text { Enfermagem }\end{array}$ & $\begin{array}{c}\text { Autarquia federal } \\
\text { ("vinculada ao Ministério } \\
\text { do Trabalho e Emprego") }\end{array}$ \\
\hline Farmacêutico & $\begin{array}{l}\text { Lei 3.820/1960; } \\
\text { Lei n. 13.021/2014 }\end{array}$ & Conselho Federal de Farmácia & $\begin{array}{l}\text { Norma não dispõe a } \\
\text { respeito }\end{array}$ \\
\hline $\begin{array}{l}\text { Fisioterapeuta } \\
\text { / Terapeuta } \\
\text { Ocupacional }\end{array}$ & $\begin{array}{c}\text { Decreto-lei n. } \\
\text { 938/1969; } \\
\text { Lei n. 6316/1975 }\end{array}$ & $\begin{array}{c}\text { Conselho Federal de } \\
\text { Fisioterapia e Terapia } \\
\text { Ocupacional }\end{array}$ & Autarquia federal \\
\hline Fonoaudiólogo & Lei n. 6.965/1981 & $\begin{array}{l}\text { Conselho Federal de } \\
\text { Fonoaudiologia }\end{array}$ & $\begin{array}{c}\text { Autarquia federal } \\
\text { ("vinculada ao Ministério } \\
\text { do Trabalho e Emprego") }\end{array}$ \\
\hline $\begin{array}{l}\text { Médico } \\
\text { Veterinário }\end{array}$ & Lei n. 5.517/1968 & $\begin{array}{c}\text { Conselho Federal de Medicina } \\
\text { Veterinária }\end{array}$ & Autarquia federal \\
\hline Médico & $\begin{array}{l}\text { Lei n. } 3.268 / 1957 ; \\
\text { Lei n. 12.842/2013 }\end{array}$ & Conselho Federal de Medicina & Autarquia federal \\
\hline Nutricionista & Lei n. 8.234/1991 & Conselho Federal de Nutrição & Autarquia federal \\
\hline Odontologista & $\begin{array}{l}\text { Lei n. 4.324/1964; } \\
\text { Lei n. 5.081/1966 }\end{array}$ & $\begin{array}{l}\text { Conselho Federal de } \\
\text { Odontologia }\end{array}$ & Autarquia federal \\
\hline Psicólogo & $\begin{array}{l}\text { Lei n. 4.119/1962; } \\
\text { Lei n. 5.766/1971 }\end{array}$ & $\begin{array}{l}\text { Conselho Federal de } \\
\text { Psicologia }\end{array}$ & Autarquia federal \\
\hline $\begin{array}{l}\text { Técnico em } \\
\text { Radiologia }\end{array}$ & Lei n. 7.394/1985 & $\begin{array}{l}\text { Conselho Nacional de } \\
\text { Técnicos em Radiologia }\end{array}$ & Autarquia federal \\
\hline
\end{tabular}

Elaboração própria.

Como se vê, cada profissão de saúde possui regras próprias que regem as diretrizes básicas de formação e exercício profissional. Para cada uma delas foi criado um conselho profissional, dotado de autonomia própria e natureza jurídica autárquica. São, portanto, instituições que se situam no mesmo nível hierárquico da Administração Pública Federal e não possuem poder umas sobre as outras. Em tese, o poder de supervisão das atividades regulatórias dos conselhos estaria sob a responsabilidade de algum órgão da Administração Direta, notadamente o 
Ministério do Trabalho. No entanto, a construção prática e teórica sobre a natureza jurídica desses conselhos acabou resultando em um grau de autonomia bastante grande, sem muitas possibilidades concretas de intervenção da Administração Direta em sua gestão.

De fato, no que se refere à natureza jurídica dos conselhos profissionais responsáveis pela regulação direta das profissões de saúde no Brasil, via de regra as leis que instituem os conselhos os definem como autarquias. Com relativa independência e competências atribuídas pelas respectivas leis, cada profissão, através de seu respectivo conselho federal (e conselhos regionais), emite resoluções sobre temas variados ligados ao exercício da profissão.

Como visto no Quadro 2, das 14 leis regulatórias, 11 dispõem expressamente que o respectivo conselho profissional é uma autarquia, e algumas o vinculam expressamente ao Ministério do Trabalho.

Além de ser expressamente reconhecido por suas leis de criação, o poder regulatório dos conselhos profissionais é reconhecido também na literatura e em decisões do Poder Judiciário. O STJ, acerca de litígio individual em que o autor pleiteava direito de ser reconhecido como especialista a despeito de regras estabelecidas pelo conselho profissional, assim se posicionou:

[...] o Poder Judiciário deve ser cauteloso ao interferir nos requisitos eleitos pelos órgãos de classe e afins para selecionar e autorizar o exercício de especialidades profissionais, especialmente na área da Saúde Pública. Com efeito, os conselhos profissionais e os órgãos de classe de natureza técnico-científica, como a agravada, são autênticos herdeiros das antigas guildas e corporações de ofício, que exerciam uma função protetiva aos interesses de seus integrantes, seja interna, mediante a realização de uma espécie de reserva de mercado, seja externa, coibindo a atuação de fornecedores ou empregadores. A função externa terminou por ser açambarcada pelos sindicatos, que a manifestam por intermédio de greves e outros mecanismos de autotutela. Historicamente, porém, a função interna transformou-se de um meio de defesa da profissão contra a entrada de novos agentes em um instrumento de defesa da própria Sociedade. A limitação do exercício profissional a pessoas habilitadas não é mais possível de ser confundida com uma mesquinha reserva ou contenção de mercado, desde que, por óbvio, efetivada nas balizas legais. Trata-se, na atualidade, de uma delegação pública aos conselhos para que selecionem seus membros e exijam-lhes probidade e perícia no desempenho de seu ofício, conforme o princípio da razoabilidade. De saliente meio de proteção de 
classe, o poder disciplinar dos conselhos tornou-se necessário mister de execução sócio-deontológica $[\ldots]^{8}$.

Embora as leis expressamente refiram os conselhos como autarquias federais, o tema ainda não está isento de discussão judicial. O Supremo Tribunal Federal (STF) já se debruçou várias vezes sobre o tema. No Mandado de Segurança n. 22.643, decidiu que os conselhos de fiscalização profissional têm natureza jurídica de autarquias. Naquela ocasião, ficou consignado que: (i) essas entidades foram criadas por lei, tendo personalidade jurídica de direito público com autonomia administrativa e financeira; (ii) exercem a atividade de fiscalização de exercício profissional que, como decorre do disposto nos artigos $5^{\circ}$, inciso XIII, e 21, inciso XXIV, é atividade tipicamente pública; (iii) têm o dever de prestar contas ao Tribunal de Contas da União ${ }^{9}$.

Ainda, o STJ, ao julgar o mérito da ADI 1.717/6-DF, declarou a inconstitucionalidade de alguns dispositivos da Lei n. 9.649/98, restando consignado que a fiscalização das profissões não pode ser delegada, por se tratar de atividade típica de Estado, que abrange o poder de polícia, de tributar e de punir. Dessa maneira, infere-se a natureza autárquica dos conselhos profissionais pelo caráter público da atividade desenvolvida por eles ${ }^{10}$.

Por fim, vale destacar também o RE 539.224, relatado pelo ministro Luiz Fux, que afirma em seu voto:

Considerando o caráter jurídico de autarquia dos conselhos de fiscalização profissional, que são criados por lei e possuem personalidade jurídica de direito público, exercendo atividade tipicamente pública, qual seja, fiscalização do exercício profissional, há de se concluir pela obrigatoriedade da aplicação a eles da regra prevista no artigo 37, II, da CF/88, quando da contratação de servidores ${ }^{11}$.

\section{Conflitos regulatórios entre as instituições reguladoras de profissões de saúde: fragilidade dos mecanismos de solução administrativa e crescente judicialização}

O atual modelo regulatório possui um conjunto expressivo de instituições reguladoras de mesmo nível hierárquico que acabam entrando em conflito em

\footnotetext{
${ }^{8}$ BRASIL. Superior Tribunal de Justiça. AgRg no Recurso Especial n. 895.881 - RJ (2006/015049-0), Relator Ministro Humberto Martins. Disponível em: <https://ww2.stj.jus.br/processo/pesquisa/?tipoPesquisa=tip oPesquisaNumeroRegistro\&termo=200601540490\&totalRegistrosPorPagina $=40$ \&aplicacao=processos. ea>. Acesso em: 03 set. 2018.

${ }^{9}$ BRASIL. Supremo Tribunal Federal. MS 22.643, Relator Ministro Moreira Alves. Disponível em: <http://redir. stf.jus.br/paginadorpub/paginador.jsp?docTP=TP\&docID=3773226>. Acesso em: 03 set. 2018.

${ }^{10}$ ADI 1717/6-DF, Rel. Ministro Sidney Sanches, DJU 28/03/2003.

${ }^{11}$ BRASIL. Supremo Tribunal Federal. RE 539.224, Relator Ministro Luiz Fux. Disponível em: <http://redir.stf. jus.br/paginadorpub/paginador.jsp?docTP=TP\&doclD=8897968>. Acesso em: 03 set. 2018.
} 
decorrência de regulação contraditória ou que evidenciam entendimentos diferentes sobre uma mesma área de atuação no campo da saúde. Na medida em que cada conselho federal de profissão de saúde possui competência normativa reguladora, um conselho pode editar normas que entram em conflito com as de outro ou outros conselhos.

Atualmente, os eventuais conflitos que surgem estão sendo levados para o Poder Judiciário, conforme se mostrará mais adiante. O Poder Executivo federal possui três espaços institucionais em sua administração direta que poderiam solucionar esses conflitos administrativamente no âmbito do próprio Poder Executivo: a MNNP-SUS; a CRTS; e a Advocacia-Geral da União.

Embora as competências legais dessas instâncias incluam a atribuição de resolver administrativamente os conflitos que emergem do modelo regulatório do exercício de profissões de saúde no Brasil, a pesquisa demonstrou que, na prática, os casos são levados para solução judicial, à luz do artigo $5^{\circ}$, inciso XXXV, da CF/1988, que assegura a todos a possibilidade de recorrer ao Poder Judiciário sempre que houver uma lesão ou ameaça de lesão a direito.

\section{Os mecanismos de solução administrativa no âmbito do Poder Executivo federal}

Os seguintes órgãos da Administração Direta possuem potencial para solucionar administrativamente os conflitos que emergem das diversas instâncias reguladoras: a MNNP-SUS; a CRTS e a Advocacia-Geral da União.

A Fórum paritário destinado à negociação coletiva acerca do tema do trabalho no âmbito do SUS, a MNNP-SUS é formalmente ligada ao CNS e ao Departamento de Gestão e da Regulação do Trabalho em Saúde (DEGERTS), que por sua vez se subordina à Secretaria de Gestão do Trabalho e da Educação na Saúde, do Ministério da Saúde (SGTES-MS). Com configuração paritária, é formada em igual proporção por representantes patronais (governo e gestores privados) e representantes dos trabalhadores (entidades sindicais), que compõe as duas bancadas da mesa. A atual mesa foi instituída por meio da Resolução n. 331/2003 ${ }^{12}$, do CNS, com a homologação ministerial e a composição paritária. As prerrogativas da MNNP-SUS são diversas e estão elencadas no artigo $5^{\circ}$ de seu regimento, destacando-se o objetivo previsto no artigo $5^{\circ}$, inciso II, que prevê que a mesa deverá "instituir processos negociais de caráter permanente para tratar conflitos e demandas decorrentes das relações de trabalho no âmbito do SUS"13.

${ }^{12}$ BRASIL. Conselho Nacional de Saúde. Resolução n. 331, de 04 de novembro de 2003. Disponível em: < http:// portalarquivos2.saude.gov.br/images/pdf/2014/marco/10/resolucao331cns.pdf>. Acesso em: 03 set. 2018.

${ }^{13}$ BRASIL. Ministério da Saúde. Mesa Nacional de Negociação Permanente do SUS. Democratização das relações de trabalho no SUS. Brasília, 2003. p. 13. Disponível em: <http://bvsms.saude.gov.br/bvs/ publicacoes/livreto_mesa.pdf>. 
A CRTS, por sua vez, é entidade colegiada e de caráter consultivo criada pela Portaria GM/MS n. 827/2004, substituída pela Portaria GM/MS n. 174/2006 ${ }^{14}$, e ligada ao DEGERTS. O artigo $1^{\circ}$ da Portaria GM/MS n. 174/2006 define três atribuições para a câmara: (i) debater ações de regulação profissional para as profissões e ocupações da área de saúde; (ii) sugerir mecanismos de regulação profissional na área de saúde; e (iii) sugerir iniciativas legislativas visando a regular o exercício de novas profissões e ocupações na área de saúde. Na composição da câmara, é de se destacar a participação de todos os conselhos presentes no Fórum Nacional dos Conselhos Federais da Área de Saúde, que em seu site ${ }^{15}$ discrimina os 14 conselhos acima listados.

Por fim, vale destacar que a própria criação da Câmara foi objeto de judicialização, uma vez que a validade da portaria que a cria foi contestada no STJ, em Mandado de Segurança ${ }^{16}$ impetrado pelo Conselho Federal de Farmácia em face do Ministro de Estado da Saúde. A tese levantada pelo conselho foi a de que a edição da portaria extrapolaria a competência regulatória do Ministério, adentrando a competência dos conselhos profissionais de saúde. Para além dos argumentos levantados, a demanda judicial demonstrou o quão conflituoso pode ser o cenário de regulação de profissões de saúde no modelo atual.

Por fim, o terceiro importante órgão que possui capacidade de solução administrativa dos conflitos regulatórios é a Advocacia-Geral da União (AGU). Com competência definida pelo artigo 18 da Lei n. 13.502/2017, ao Advogado-Geral da União - o mais elevado órgão de assessoramento jurídico do Poder Executivo - incumbe assessorar o presidente da República em assuntos de natureza jurídica, elaborando pareceres e estudos ou propondo normas, medidas e diretrizes; assisti-lo no controle interno da legalidade dos atos da Administração Pública Federal; sugerir-lhe medidas de caráter jurídico reclamadas pelo interesse público; e lhe apresentar as informações a serem prestadas ao Poder Judiciário quando impugnado ato ou omissão presidencial; dentre outras atribuições fixadas na Lei Complementar n. $73 / 1993^{17}$. Encontra-se no plexo de atribuições da AGU solucionar conflitos jurídicos entre diferentes órgãos e instituições da União, tais como os ministérios e os conselhos. No entanto, a pesquisa demonstra que esta via não vem sendo utilizada, e que a judicialização dos conflitos mostra-se como o mecanismo preferencial de "solução" atualmente.

\footnotetext{
${ }^{14}$ BRASIL. Ministério da Saúde. Portaria n. 174, de 27 de janeiro de 2006. Reestrutura a Câmara de Regulação do Trabalho em Saúde. Disponível em: <http://bvsms.saude.gov.br/bvs/saudelegis/gm/2006/ prt0174_27_01_2006.html>. Acesso em: 25 ago. 2015.

${ }^{15}$ FORUM DOS CONSELHOS FEDERAIS DA ÁREA DA SAÚDE. Disponível em: <http://www.fcfas.org.br/>. Acesso em: 25 ago. 2015.

${ }^{16}$ BRASIL. Superior Tribunal de Justiça. Mandado de Segurança: MS 9596 DF 2004/0036903-9. Disponivel em: <http://stj.jusbrasil.com.br/jurisprudencia/7166437/mandado-de-seguranca-ms-9596df-2004-0036903-9>. Acesso em: 26 ago. 2015.

${ }^{17}$ BRASIL. Lei Complementar n. 73, de 10 de fevereiro de 1993. Institui a Lei Orgânica da Advocacia-Geral da União e dá outras providências. Disponível em: <http://www.planalto.gov.br/ccivil_03/LEIS/LCP/Lcp73. htm>. Acesso em: 03 set. 2018.
} 


\section{A judicialização dos conflitos regulatórios}

Em um ambiente regulatório com múltiplos centros decisórios e uma ampla atividade a ser regulada, é de se esperar que existam conflitos. Assim é no campo das profissões de saúde no Brasil. Cada uma 14 profissões elencadas pelo CNS possui uma lei que a regulamenta em termos gerais e fornece competências para que seu respectivo conselho profissional proceda com a regulamentação infralegal. Além disso, a administração pública direta ainda possui competências para regulamentar tais profissões, especificamente no âmbito dos ministérios da Saúde e da Educação.

Dessa forma, surgem conflitos de competência que acabam sendo resolvidos apenas judicialmente, chegando inclusive aos Tribunais Superiores. Seguindo os critérios adotados e indicados na metodologia, foram localizadas 37 ações julgadas no STJ que se referem expressamente a conflitos regulatórios no campo das profissões de saúde.

O Quadro 3 apresenta o número de ações que representam conflitos regulatórios em que cada conselho figura como autor ou réu.

Quadro 3. Judicialização dos conflitos regulatórios entre os conselhos de saúde no Superior Tribunal de Justiça

\begin{tabular}{lcc}
\hline Entidade & $\begin{array}{c}\text { Número de } \\
\text { processos em que } \\
\text { é autor (a partir da } \\
\text { primeira instância) }\end{array}$ & $\begin{array}{c}\text { Número de } \\
\text { processos em que } \\
\text { é réu (a partir da } \\
\text { primeira instância) }\end{array}$ \\
\hline Conselho Federal de Biologia & 0 & 0 \\
\hline Conselho Federal de Biomedicina & 0 & 0 \\
\hline Conselho Federal de Educação Física & 1 & 3 \\
\hline Conselho Federal de Enfermagem & 0 & 4 \\
\hline Conselho Federal de Farmácia & 11 & 3 \\
\hline Conselho Federal de Fisioterapia e Terapia Ocupacional & 1 & 0 \\
\hline Conselho Federal de Fonoaudiologia & 0 & 1 \\
\hline Conselho Federal de Medicina & 10 & 7 \\
\hline
\end{tabular}

\section{Considerações finais}

A pesquisa apresentada neste artigo lança algumas luzes sobre 0 atual modelo de regulação de profissões de saúde vigente no Brasil e contribui para o aprofundamento dos conhecimentos sobre o tema da regulação de profissões de saúde no Brasil, possibilitando visualizar algumas possibilidades de aperfeiçoamentos do atual modelo jurídico-institucional brasileiro. Os resultados descritos chamam a atenção para diversos aspectos da regulação atual que merecem ser mais bem conhecidos, em especial os conflitos regulatórios entre os diversos conselhos e entre os conselhos e os ministérios. 
Também merece atenção maior a compreensão da relação existente entre a regulação do exercício profissional com a formação recebida pelos profissionais de saúde, bem como a relação entre a regulação do exercício profissional e as políticas públicas de Estado e de governo estabelecidas no âmbito do SUS pelas gestões federal, estaduais e municipais.

Para além de uma melhor compreensão da natureza dos conflitos e das suas causas, a pesquisa também possibilitou a visão de possíveis cenários de aperfeiçoamento regulatório que, certamente, merecem aprofundamento.

A CRTS, criada em 2004 e reformulada em 2006 pela Portaria GM/MS n. 174/2006, pode ser aperfeiçoada em sua organização e competências para que passe a representar, efetivamente, uma instância administrativa de solução de conflitos apta a evitar a judicialização.

Tendo em vista a inafastabilidade do Poder Judiciário para a solução de conflitos no âmbito do Estado Democrático de Direito brasileiro, e tendo em vista que o atual modelo enseja uma judicialização rotineira dos conflitos regulatórios entre as profissões de saúde, recomenda-se que seja realizada uma política de aproximação do Poder Executivo com o Poder Judiciário para discussões técnicas sobre os tipos de conflitos de regulação de profissões judicializados e as melhores formas de solução articulada entre os poderes. Esse tipo de aproximação vem sendo feito no campo mais geral conhecido como judicialização da saúde pode ser ampliado para que também se discuta a judicialização dos conflitos regulatórios entre as profissões de saúde.

\section{Referências}

CHEVALIER, Jacques. Vers un droit posmoderne. In: CLAM, Jean; MARTIN, Gille (Dirs.). Transformations de la regulation juridique. Paris: LGDJ, 1998.

FORUM DOS CONSELHOS FEDERAIS DA ÁREA DA SAÚDE. Disponível em: <http:// www.fcfas.org.br/>. Acesso em: 25 ago. 2015.

SANTOS, Fausto Pereira dos; MERHY, Emerson Elias. A regulação pública da saúde no Estado brasileiro: uma revisão. Interface, Botucatu [online], v. 10, n. 9, p. 25-41, 2006. ISSN 1414-3283. Disponível em: <http://www.scielo.br/pdf/icse/v10n19/a03v1019.pdf>. http://dx.doi.org/10.1590/S1414-32832006000100003.

SUNDFELD, Carlos Ari. Direito administrativo econômico. 1. ed. São Paulo: Malheiros Ed., 2002.

\section{Agradecimentos}

Agradecemos aos pesquisadores Gianítalo Germani e Renata Rothbarth pelas contribuições dadas ao longo da pesquisa, especialmente na coleta de dados e na participação nas análises de parte dos dados coletados. 
Aith F. M. A., Germani A. C. C., Balbinot R., Dallari S. G.

Fernando Mussa Abujamra Aith - Professor Titular da Faculdade de Saúde Pública da Universidade de São Paulo (FSP/USP). Livre-Docente em Teoria Geral do Estado pela Faculdade de Direito da Universidade de São Paulo (FADUSP); pós-doutor em Direito Público pela Faculdade de Direito da Université Paris 2 (França); doutor em Saúde Pública pela FSP/USP; mestre em Filosofia e Teoria Geral do Direito pela FADUSP; graduado em Direito pela FADUSP. Codiretor científico do Núcleo de Pesquisa em Direito Sanitário da USP (NAP-DISA/USP). São Paulo/SP, Brasil.E-mail: fernando.aith@usp.br

Ana Claudia Camargo Germani - Doutora e mestre pela Faculdade de Medicina da Universidade de São Paulo (FMUSP); graduada em Medicina pela Faculdade de Medicina do ABC. Professora doutora da FMUSP. São Paulo/SP, Brasil.

Rachelle Balbinot - Pós-Doutora em Saúde Coletiva pela Universidade Federal de São Paulo; pós-doutora em Saúde Púbica pela Universidade de São Paulo (USP); doutora em Integração da América Latina pela USP; mestre em Direito pela Universidade Federal de Santa Catarina; graduada em Direito pela Universidade Federal de Santa Maria. Pesquisadora do Núcleo de Pesquisa em Direito Sanitário da USP (NAP-DISA/USP). São Paulo/SP, Brasil.

Sueli Gandolfi Dallari - Professora Titular da Faculdade de Saúde Pública da Universidade de São Paulo (FSP/USP). Pós-Doutora em Direito Médico pela Université Paris 12 (França); pós-doutora em Saúde Pública pela Columbia University (Estados Unidos); livre-docente; doutora e mestre em Saúde Pública pela FSP/USP. Coordenadora científica do Núcleo de Pesquisa em Direito Sanitário da USP (NAP-DISA/USP). Advogada. São Paulo/SP, Brasil. 